\section{Deadly contests: an economic note on al Qaeda's reward system}

\section{Raul Caruso and Andrea Locatelli}

$\mathrm{T}$

he aim of this article is to analyze al Qaeda's modus operandi in light of the economic theory of contests. Al Qaeda can be viewed as a contest organizer rewarding an indivisible prize that, we assume, consists of official membership and economic rewards. The contest is then joined by candidate terrorist groups that compete by maximizing efforts to win the prize, that is, maximizing the number of casualties. As will be seen, this logic has various pros - and some cons. In order to devise an effective counterstrategy, governments should target two key elements of this contest: al Qaeda's communication strategy and the setting of the prize.

The article is divided into three

Al Qaeda can be viewed as a contest organizer rewarding an indivisible prize - membership and economic rewards. sections, the first of which describes al Qaeda's main features. To account for al Qaeda's relationship with its cells, section two presents insights drawn from the economic theory of contests. Section three

briefly discusses tentative strategies for counterterrorism.

How is al Qaeda different from other terrorist organizations?

When compared to traditional terrorist groups, al Qaeda displays several novel elements. Among its defining features, Audrey Kurth Cronin suggests four main characteristics: (1) fluid organization; (2) methods of recruitment; (3) financing instruments; and (4) the use of communications media. ${ }^{1}$ While all of them are relevant when it comes to framing a sound counterstrategy, for our purposes it is critical to focus attention exclusively on the way al Qaeda cells are related to, and interact with, each other, that is, its organizational dimension broadly conceived.

It is this organizational feature that makes terrorists so difficult to hunt down. Indeed, thanks to the flexibility embedded in its structure, al Qaeda is continuously evolving. Indeed, rather than being an organization, al Qaeda comes closer to the original meaning of its name: a concept, an idea, or a mission. To describe its specificity, analysts have coined a plethora of terms such as network, group, movement, and clique, in other words, anything denoting a flexible structure with fuzzy boundaries. Considering al Qaeda as a network is not only in line with recent empirical findings but is also helpful in understanding the principles and the logic underlying its functioning. ${ }^{2}$
For the whole network, the lack of a clear hierarchical line of command that is inherent in such a structure results in flexibility and autonomy as well as in resilience to penetration and compromise. ${ }^{3}$ In particular, this flexibility allows for a novel recruitment system that is clearly crucial when considering al Qaeda's survival and spread on a worldwide scale. In fact, recent work suggests that the recruiting process may now resemble a kind of voluntary application to join the organization. In this view, new groups are involved in the organization as the result of a selection process among different volunteers. ${ }^{4}$ The rise of the so-called self starters ${ }^{5}$ is taken as evidence of this, that is, groups with little or no initial affiliation with the network perpetrating terrorist attacks on their own initiative. This allows al Qaeda to extend its membership almost infinitely, simply because new groups can be affiliated at any time without an institutionalized recruitment procedure. Although a conjecture, it may be assumed that the number of potential applicants is much higher than the promised membership. This situation is especially beneficial for al Qaeda for at least three reasons. First, there is no need for bin Laden and his followers to invest resources in recruitment drives. Second, and most importantly, an abundance of applications would allow al Qaeda to be selective in granting membership. The only weakness of the self-starters system is that, by virtue of the spontaneous origins of would-be terrorists, the command and control capabilities are quite limited. As a side effect, therefore, al Qaeda could be cited and get stuck in actions far from its leaders' main interests Also, and partially related to the second point, the potential of ideology as a common denominator should not be exaggerated as the ideological appeal is a necessary but hardly sufficient condition.

In the next section we turn to the contribution of the economic theory of contests as this could be a useful theoretical framework to understand how candidate groups volunteer to exert effort in order to get affiliated with the al Qaeda network. Before proceeding in this direction, it is worth noting that recently a different interpretation has been proposed. Specifically, it has been argued that terrorist cells behave according to an open-source mechanism. ${ }^{6}$ This interpretation mainly focuses on the structure of the network: terrorists would be akin to developers of free, Linux-style software. Some factors could make this a fitting interpretation: (1) the lack of a rigid hierarchical structure; (2) the decentralized organization of the network; (3) the initiative of developers; and (4) the spontaneous elitist evolution of contributors. However, in our view other factors make such an interpretation incorrect. For example, in an open-source mechanism, codevelopers produce a public good. They can consume this public good and such consumption positively enters the utility function of both developers and users. By contrast, terrorist cells produce a public bad. They cannot consume the good itself and it cannot enter positively any utility function. ${ }^{7}$ As to the organization of the structure, here too are some characteristics that limit the usefulness of this kind of interpretation. In the open-source mechanism, a developer faces a publicly available opportunity cost to her or his time. While developing an open-source project, he or she must give up the development of other 
projects. This is possible because programming skills are pervasive and simply signaled. Therefore, developers clearly face an opportunity cost which is public information. This seems not to be the case with terrorists. Since terrorism is a secret activity by definition, terrorists would not be engaged in other activities. Terrorist skills are not pervasive and, in most cases, they cannot be disclosed. The opportunity cost faced by candidate terrorists is private information. Last but not least, in an open-source structure, developers can communicate and interact with each other. This does not seem to be the case, or not nearly as much, with terrorist networks. It has been shown that, unlike conventional social networks, terrorist networks do not need to experience frequent and dense communication. Rather, in most cases ties and connections are activated only when they are assumed to be necessary. ${ }^{8}$

Potentially fruitful insights that could still be drawn from the open-source interpretation relate to the motivations of developers. Open-source is characterized by two distinct incentives leading to delayed payoffs: first, a career concern incentive, namely the "bid" on future well-paid job offers and, second, the peer-recognition incentive (something akin to academic research). Both fall under the heading of signaling incentive, which according to Lerner and Tirole strongly relies on (1) the highest possible visibility of performance to the relevant audience; (2) the highest possible impact of effort on performance; and (3) the highest perceived causality between performance and talent. However, these elements also fit with contest theory, to which we now turn.

Some insights from contest theory

We now elucidate some conditions and the logic that may underlie al Qaeda's peculiar recruiting process. There is a growing awareness among economists and other social scientists that many phenomena can be modeled as contests. A contest is commonly defined as a game in which rational agents (players) compete for a prize by making irreversible outlays. This constitutes the main difference to auctions, in which agents do not bear the cost of the bids entirely by themselves. This is also the rationale for labeling contests as all-pay auctions. ${ }^{9}$

\section{The role of contest effort}

Literature on contests commonly involves the concept of Nash equilibrium. A strategy is assumed to be a Nash equilibrium when no player involved has any incentive to deviate from it. The emergence of a Nash noncooperative equilibrium commonly occurs when agents have no opportunity for coordination. This is the classic case of a prisoner's dilemma in which each actor chooses its favorite strategy even though this may lead to a suboptimal joint outcome because they are unable to coordinate. The lack of coordination leads to a noncooperative (or non-coordinated) equilibrium. As rational agents, the players maximize only their own individual expected payoff.
Although it seems trivial, the concept of maximizing agents becomes fundamental when analyzing agents' behavior in contests. Consider two simple examples. In a race athletes cannot coordinate their actions. In the presence of an indivisible prize (a winner-take-all contest) they will put in their maximum effort to win the prize. In such a case, coordination is clearly not feasible. Only one player can win. There is no alternative strategy. Agents play à la Nash and maximize their efforts in order to maximize their own payoffs. In a similar fashion, scholars competing for research grants cannot coordinate with each other. When grants are assigned on a personal basis and there is no opportunity to agree on a predetermined sharing of the "cake," the only feasible strategy is to write the best possible research proposal.

Hereafter we mention some common findings of contest literature that might be useful for our analysis. In particular, we are interested in accounting for agents' behavior and efforts. To start, the level of the effort made by every agent is strictly correlated to the value of the prize, that is, the higher the valuation of the prize, the higher the commitment to put maximum effort into the contest. Second, each agent knows that the probability of winning the contest is increasing in its own effort and decreasing in other players' efforts. That is, in the simplest case of two agents, A and $\mathrm{B}$, the probability of agent $\mathrm{A}$ of winning the contest is higher when it makes a bigger effort than does agent B - and vice versa. Therefore, the only feasible strategy for both $\mathrm{A}$ and $\mathrm{B}$ will be exerting the maximum possible effort. This way, each player can attain maximum payoff. Contest theory thus predicts that maximizing behavior is the strategy used by each agent. This can be generalized to the presence of a larger number of contestants. In a multi-agent scenario, however, the theory also predicts that total effort decreases with the number of contestants. That is, when agents are aware that the contest is joined by more agents, individual effort will decrease. By the same token, the sum of all individual efforts increases.

Of course, these general predictions about agents' behavior are derived under ceteris paribus conditions. Still, in general, the predictions hold even when other factors affect the effectiveness of effort. For expository reasons, we indicate two candidate subsets of interacting factors: individual characteristics and exogenous characteristics. Regarding the first, consider the existence of individuals' or groups' different talents and abilities. If one views a contest somewhat abstractly as a production function where monetary reward is the "output" obtained, then effort constitutes the "input." Innate talent and acquired ability constitute a "technology" translating a certain level of effort into a probability of successfully producing the desired output. The impact of different abilities is clearer in the presence of a winner-take-all contest. Take again the example of a race. Since athletes are expected to put their maximum effort into the race, and given that their level of effort depends upon the value of the prize, they would make the same effort. In such a case, the outcome of the contest will be determined - everything else being equal - by abilities. Of course, abilities can be exogenously given and refer to personal talents given by nature, but they can also be related to specific positive investments made by 
agents. Still, this is not what really matters when analyzing a contest. What matters is that if agents are not able to update their own abilities at different stages of the game, their efforts will be fruitless.

\section{The role of contest design}

As regards exogenous conditions, consider the design of the contest. In order to influence the total amount of effort exerted, the agent providing the contest prize can modify the architecture of the contest. The simplest case is that of providing different prizes. This is commonly the case with sport contests where prizes are offered for the winner, but also for the runner-up. Moldovanu and Sela offer a brilliant theoretical contribution in this respect, showing that in the presence of concave cost functions, a single prize constitutes the optimal design to maximize effort. ${ }^{10}$ In contrast, in the presence of convex cost functions - that is, when effort is increasingly costly, or when cost increases as the contest goes on - a multiplicity of prizes constitute the optimal design choice. In fact, when rational agents know that several prizes are provided, and given available information about other contestants' abilities, they will put maximum effort into the contest. Even if they are aware that they cannot win the contest, they still expend maximum effort to get one of the other prizes. This is the case in sports such as cycling, where different prizes are provided by organizers, and the total effort of participants is maximized. But when the cost function is not convex - does not increase with the effort - a single prize is the best contest design. Here, too, the designer's objective is maintained in that the level of total effort is maximized. Offering only one prize guarantees that no player will give up. This is true in particular when players do not have information about other contestants' abilities.

The role of prize valuation

The storyline thus far relies on the assumption that agents involved in a contest are symmetric apart from their own abilities. The notion of differences in abilities is commonly recognized among students of political science. But asymmetry can take other forms. In the realm of strategic interactions, what is also affecting agents' behavior is asymmetry in terms of available information.

The simplest case refers to asymmetry in the valuation of the prize. ${ }^{11}$ That is, when its value is not publicly disclosed but privately inferred, then agents likely will value the contest prize differently. And because the level of effort is positively correlated to the value of the prize, different valuations lead to different levels of effort made by agents. Scholars find that agents that value the stake more highly undertake a bigger contest effort than low-valuation participants. In particular, Hillman and Riley show that asymmetric valuation deters participation by low-valuation agents. Consider a contest with only two players, A and B, with identical abilities. If A has a higher valuation of the prize, it will exert itself more. As a consequence it will be the favorite to win. Agent B, the "underdog," will exert itself less. Therefore, increasing the favorite's valuation increases its effort but decreases the effort of the underdog. This result may hold even if agent B (the lowvaluation agent) has superior abilities. In fact, it would be possible to demonstrate that even if agent $\mathrm{A}$ is less skilled in terms of abilities, it will always be the favorite regardless of its inferiority so long as its prize valuation is sufficiently high relative to the other player: asymmetry in the prize valuation can be a driving force.

To sum up: (1) all players maximize their own effort; (2) in the presence of asymmetry in the valuation of the prize, low-valuation players will give up; (3) lowability players will also give up; and, although not explored here, (4) the probability of collusion among players found has been to be low. ${ }^{12}$

Al Qaeda fits into the theory by portraying it as a contest organizer providing an indivisible prize to the best terrorist group. From time to time, bin Laden and his followers may start a competition among groups loosely related to the network. The prize may be viewed as some sort of ideological blessing (being accepted as a full and "honorable" member of the organization) as well as an economic reward. ${ }^{13}$ More important, for our purpose, are the insights that contest theory offers about the way candidate cells compete with each other.

\section{The role of information}

The key feature relates to information. All the participants are privately informed about their own abilities - each group knows how much it can achieve - but they are unaware of each others' potential. This, in turn, creates a favorable condition for the contest designer, because all groups are forced to give their best and maximize their respective efforts. But information can also be seen as the process used by groups to signal their commitment and ability (and, conversely, as the way bin Laden monitors their actions). When it comes to terrorist attacks, monitoring and information costs are close to zero: when a terrorist group bombs an embassy or a trade center with dozens of casualties anywhere in the world, the event is extensively broadcast by international mass media. As a result, the link between effort and reward is quite direct: the greatest effort is supposed to guarantee the prize. Put differently, each group knows that in order to win the prize it will have to maximize the number of casualties. Moreover, because groups can value the prize to be awarded differently, a spontaneous partitioning between high-ability and low-ability groups is to be expected.

The implication of this logic is twofold. On the one hand, contrary to common 
wisdom, mass killing and the resulting psychological effect is not an end in itself, but rather a means for aspiring groups to win al Qaeda's prize. In this view, target selection - train stations, malls, and hotels — is not just the consequence of ideological consideration, but is a matter of tactical calculation: these sites host hundreds of appealing targets, are easy to strike, and highly visible in terms of media coverage. A second implication is that according to the model a terrorist action per se is not enough to automatically grant membership. Eventually, as a sort of ex-post franchising, al Qaeda reaps the reputation or image benefits of the most successful attacks while paying, all things considered, a limited price. ${ }^{14}$

\section{Conclusion}

The previous paragraphs apply insights drawn from contest theory to explain some of al Qaeda's more puzzling features. As witnessed first by the attacks in Madrid (2004) and London (2005), and more recently by the plots unveiled in London and Glasgow in July 2007, terrorist actions can look more like the result of self-starters' initiatives than elaborate, centralized, top-down plans. This practice represents a truly problematic departure from the past. From a counterterrorism perspective, the rise of autonomous violence-prone groups found Western intelligence services basically unprepared. In the words of the British Intelligence and Security Committee's report: "We remain concerned that across the whole of the counter-terrorism community the development of the home-grown threat and the radicalization of British citizens were not fully understood or applied to strategic thinking." 15

When explaining al Qaeda's recruitment process, contest theory also sheds some light on the role of information and communication in connecting the various nodes that constitute the structure of its network. Conceived broadly, communication merely refers to the use of mass media or the Internet by bin Laden and his followers. Mastering advanced technologies proved critical in al Qaeda's ability to talk to multiple audiences, like potential new members, hostile governments, and public opinion worldwide. However, this blurs the line between internal and external communication. The model provided by contest theory unveils the relevance of the internal front of communication, that is, the way in which information circulates among various bodies of the organization. As mentioned, for bin Laden most of the advantages of starting contests derive from asymmetrical information: indeed, collusion among competing groups is hindered by a lack of knowledge of each others' abilities and motivations; likewise, scarce information on the criteria used to allocate the prize forces competing groups to maximize their effort. But there are also some potential weaknesses with this theory. For example, the logic of group competition inherent in contests is limited to apply only under certain conditions such as private and asymmetric information. As a result, counterterrorism should first aim at tackling these conditions.

Two broad policy prescriptions emerge from our analysis. The first is to discredit bin Laden's promise, or, to put it in more sophisticated terms, to falsify and confuse the kind of information that terrorist candidates receive. The implicit assumption of any contest is that the organizer will certainly reward the winner. Thus, the success of a contest rests to a large extent upon trust. Undermining the trust extremist candidates feel would presumably weaken the process of recruitment. Perhaps it is up to the intelligence community to perform this task and adopt instruments to interfere with al Qaeda's communication. However, this is a sensitive issue as evidently the risk involved in some intelligence practices for democratic countries is to disregard individual freedoms in favor of public security. ${ }^{16}$ Following this lead, terrorist violence would certainly not be eradicated, but it would be much harder for bin Laden to sustain contest credibility among potential applicant groups.

The second prescription concerns funding. Insofar as bin Laden's reward to self-starters is monetary, hindering al Qaeda's capacity to distribute funds becomes a critical issue. This can be done by breaking down the flow of money at the lowest level of the chain, that is, before it gets into local groups' hands. If counterterrorism can deny them their economic reward, bin Laden's credibility as a contest organizer will be challenged. Counterterrorism would have to track financial flows in order to prevent local groups from enjoying rewards for their actions.

The insights suggested by our analysis are empirically limited by the lack of reliable information on the network. Because no public confession or statement has been made by al Qaeda operatives on bin Laden's reward strategy, we have to focus exclusively on the output of the process - al Qaeda's attacks. As a consequence of this limit, several paths for future research are open. In particular, future analyses should investigate in depth the terms of the contest. How does bin Laden initiate a contest? How does he reward successful applicants, that is, what weight do ideological blessing and monetary remuneration carry? ${ }^{17}$ Is the contest entered into by several participants simultaneously, or do applicants play sequentially until bin Laden's goal is achieved? Finally, how does one jam or deter this strategy? These questions are beyond the limits of this article. Addressing them will require refining, and perhaps amending, the interpretations offered here.

Notes

Raul Caruso (corresponding author) is a research fellow at the Institute of Economic Policy and Professor of International Economics at Università Cattolica del Sacro Cuore, Milan. Contact: raul.caruso@unicatt.it. Andrea Locatelli is lecturer at Università Cattolica del Sacro Cuore, Milan, and fellow at Dipartimento Politica, Istituzioni e Storia, University of Bologna. Contact: andrea1.locatelli@unicatt.it.We thank anonymous referees for their comments that helped to improve the argument advanced in this article.

1. Kurth Cronin (2006, pp. 32-39). 
2. Meaning: As noted by many commentators, the original meaning of al Qaeda is essentially "the base," "the foundation," or even "the method," which underlines the organization's catalytic role among different groups. Terms: Coll and Glasser (2005). Findings: Sageman (2004).

3. Structure: Jackson (2006, pp. 247-248). Networks: For an in-depth discussion of networks, see Arquilla, Ronfeldt (2001).

4. Cozzens (2005); Sageman (2004, p. 110).

5. Kirby (2007); Sageman (2008).

6. The open-source interpretation of al Qaeda is in Robb (2007). We are grateful to Jurgen Brauer for bringing the issue to our attention.

7. Public good: see Lerner and Tirole (2002). A public bad is a diffused negative externality recalling the idea of "atmosphere" externality as developed by Meade (1952).

8. See Krebs (2002); Brams, Mutlu, and Ramirez (2006).

9. Traditional contest models are formally grounded on Tullock (1980) and found seminal explanations in O'Keeffe, Viscusi, and Zeckhauser (1984, pp. 27-56); Rosen (1986); Dixit (1987). The first and seminal application was developed by Tullock (1980) for rent-seeking phenomena.

10. Moldovanu and Sela (2001).

11. For details on the ideas in this paragraph, see Hillman and Riley (1989); Nti (1999; 2004).

12. The possibility of collusion between heterogeneous agents in a contest has been analyzed in Caruso (2008).

13. Al Q aeda has given grants to local groups that devised promising plans for attacks. See Hoffman (2003).

14. See Farah and Finn (2003); Benjamin (2003).

15. Government Response to the Intelligence and Security Committee's Report into the London Terrorist Attacks on 7 July 2005 (May 2006).
16. Wilkinson (2000).

17. Whenever agents are partitioned into status categories according to their performance (top-class, low-class, and so on), a reasonable hypothesis is that the terrorist groups involved in this kind of contest care more about their relative status than about the potential monetary reward. Social and cultural considerations connected to a concern for relative position do constitute important determinants affecting the performance of agents. This kind of behavior can be strengthened in the presence of a deep ideological and religious motivation. See Moldovanu, Sela, and Shi (2007).

\section{References}

Arquilla, J. and D. Ronfeldt, eds. 2001. Networks and Netwars: The Future of Terror, Crime and Militancy. Santa Monica, CA: RAND.

Benjamin, D. 2003. “Are the Sparks Catching?” The Washington Post. 23 November 2003.

Brams, S.J., H. Mutlu, and S.L. Ramirez. 2006. "Influence in Terrorist Networks: From Undirected to Directed Graphs." Studies in Conflict and Terrorism, Vol. 29, No. 7, pp. 703-718.

Caruso, R. 2008. "Reciprocity in the Shadow of Threat." International Review of Economics, Vol. 55, No. 1/2, pp. 91-111

Coll, S. and S. Glasser. 2005. "Terrorists Turn to the Web as Base of Operations." The Washington Post. 7 August 2005.

Cozzens, J. 2005. "Islamist Groups Develop New Recruiting Strategies." Jane's Intelligence Review. 1 February 2005.

Dixit, A. 1987. "Strategic Behavior in Contests." American Economic Review, Vol. 77, No. 5, pp. 891-898.

Farah, D. and P. Finn. 2003. "Terrorism, Inc.: Al-Qaida Franchises Brand of Violence to Groups Across World." The Washington Post. 21 November 2003.

Farley, J. 2003. "Breaking Al Qaeda Cells: A Mathematical Analysis of Counterterrorism Operations (A Guide for Risk Assessment and Decision Making)." Studies in Conflict and Terrorism, Vol. 26, No. 6, pp. 399-411.

Hillman, A. and J.G. Riley. 1989. "Politically Contestable Rents and Transfers." Economics and Politics, Vol. 1, No. 1, pp. 17-39.

Hoffman, B. 2003. "The Leadership Secrets of Osama bin Laden: The Terrorist as CEO." Atlantic Monthly, (April), pp. 26-27.

Hoffman, B. 2004. "The Changing Face of al-Qaida and the Global War on Terrorism." Studies in Conflict and Terrorism, Vol. 27, No. 6, pp. 93-104.

[IISS] International Institute for Strategic Studies. 2004. Strategic Survey 2003/4. Oxford: Oxford University Press.

Kirby, A. 2007. “The London Bombers as 'Self-Starters': A Case Study in Indigenous 
(C) www.epsjournal.org.uk - Vol. 3, No. 2 (2008)

Radicalization and the Emergence of Autonomous Cliques." Studies in Conflict and Terrorism, Vol. 30, No. 5, pp.415-428.

Krebs, V.E. 2002. "Mapping Networks of Terrorist Cells." Connections, Vol. 24, No. 3, pp.43-52.

Kurth Cronin, A. 2006. "How al-Qaeda Ends: The Decline and Demise of Terrorist Groups." International Security, Vol. 31, No. 1, pp. 32-39.

Jackson, B. 2006. "Groups, Networks, or Movements: A Command-and-Control-Driven Approach to Classifying Terrorist Organizations and Its Application to Al Qaeda." Studies in Conflict and Terrorism, Vol. 29, No. 3, pp. 241-262.

Lerner, J. and J. Tirole. 2002. "Some Simple Economics of Open Source." Journal of Industrial Economics, Vol. 50, No. 2, pp. 197-234.

Meade, J.E. 1952. "External Economies and Diseconomies in a Competitive Situation." The Economic Journal, Vol. 62, No. 245, pp. 54-67.

Moldovanu, B. and A. Sela. 2001 "The Optimal Allocation of Prizes in Contests." American Economic Review, Vol. 91, No. 3, pp. 542-558.

Moldovanu, B., A. Sela, and X. Shi. 2007. "Contests for Status.” Journal of Political Economy, Vol. 115, No.2, pp. 338-363.

Nti, K. 1999. "Rent-Seeking with Asymmetric Valuations.” Public Choice, Vol. 98, pp. 415-430.

Nti, K. 2004. "Maximum Efforts in Contests with Asymmetric Valuations." European Journal of Political Economy, Vol. 20, pp. 1059-1066.

O'Keeffe, M., K. Viscusi, and R. Zeckhauser. 1984. "Economic Contests: Comparative Reward Schemes." Journal of Labor Economics, Vol. 2, No. 1, pp. 27-56.

Robb, J. 2007. Brave New World: The Next Stage of Terrorism and the End of Globalization. San Francisco, CA: Wiley \& Sons.

Rosen, S. 1986. "Prizes and Incentives in Elimination Tournaments." American Economic Review, Vol. 76, No. 4, pp. 701-715.

Sageman, M. 2004. Understanding Terror Networks. Philadelphia, PA: The University of Pennsylvania Press.

Sageman, M. 2008. Leaderless Jihad. Terror Networks in the Twenty-First Century. Philadelphia, PA: The University of Pennsylvania Press.

Tullock, G. 1980. "Efficient Rent Seeking,” pp. 97-112 in J. Buchanan, R. Tollison and G. Tullock, eds. Toward a Theory of the Rent-seeking Society. College Station, TX: Texas A\&M University Press.

Wilkinson, P. 2000. Terrorism Versus Democracy: The Liberal State Response. London: Frank Cass. 